\title{
LONG-TERM PATENCY RATE OF AV-FISTULA IN RELATION TO DIAMETER OF ARTERIOTOMY 3 MM VS $<3$ MM
}

\author{
Munagala Swatantra Bharathi', Kondapalli Sivarama Krishna², Naveen Kumar', Satya Varaprasad4, P. V. Sudhakar ${ }^{5}$, J. V. Siva Priya ${ }^{6}$, \\ Pilla Sidhartha
}

\begin{abstract}
${ }^{1}$ Assistant Professor, Department of Plastic Surgery, Siddhartha Medical College, Vijayawada, Andhra Pradesh, India. ${ }^{2}$ Assistant Professor, Department of Neuro Surgery, Siddhartha Medical College, Vijayawada, Andhra Pradesh, India. ${ }^{3}$ Civil Assistant Surgeon, Department of Plastic Surgery, ENT General Hospital., Visakhapatnam, Andhra Pradesh, India. ${ }^{4}$ Director, Visakha Institute of Medical Sciences, Visakhapatnam, Andhra Pradesh, India.

5Principal, Andhra Medical College, Visakhapatnam, Andhra Pradesh, India.

${ }^{6}$ Postgraduate Student, Department of Community Medicine, Andhra Medical College, Visakhapatnam, Andhra Pradesh, India. ${ }^{7}$ Consultant Plastic Surgeon, Department of Plastic Surgery, Care Hospital, Visakhapatnam, Andhra Pradesh, India.
\end{abstract}

ABSTRACT
BACKGROUND
People who develop end stage renal disease often need dialysis in which a machine performs a basic function of kidney.1,2 Before a
patient begins dialysis treatment, a minor surgical procedure called arteriovenous (AV) fistula is done. Creating an AV fistula
allows arterial pressure to enlarge the vein over time better enabling it to receive the volume of blood coming back into the body.
The rising prevalence of end stage renal disease (ESRD) and the consequent impact on heathcare economics has resulted in
increasing focus on delivery of vascular access care which is considered the Achilles' heel of haemodialysis. The autologous
arteriovenous fistula is the acceptable gold standard mode of vascular access for haemodialysis in terms of longevity, patient
morbidity and health care costs in developing country like India. Brescia-Cimino Radio Cephalic Arterio-Venous fistula (RC-AVF) at
the wrist remains the vascular access of choice for haemodialysis even today ${ }^{3}$. Creating an autologous fistula with arteriotomy
diameter of $3 \mathrm{~mm}$ in longitudinal axis of radial artery gives better success rate and long duration of patent functioning fistula.

\section{MATERIALS AND METHODS}

Hundred patients with ESRD were selected for whom arteriovenous fistula, radio cephalic end to side anastomosis was done. A study was done regarding the long-term patency rate by taking arteriotomy diameter into consideration. In $50 \mathrm{of}$ them, $3 \mathrm{~mm}$ arteriotomy was done- group 1; and in another 50 of them $<3 \mathrm{~mm}$ arteriotomy was done- group 2 patients. Two groups were compared with study variables by mean duration of surgery, intra operative bleeding, obtaining immediate thrill, visibility of immediate pulse and post operative follow up for noting the patency and functioning fistula was done every 1, 3 and 6 months.

\section{RESULTS}

The study results were analysed statistically by means of Mean, Standard deviation, Chi-square test and Fishers exact test for significance. Of the 100 patients, most of them were males with ESRD (74\%), mean age of all patients in this study was $49.5+10.9$ years., the mean duration of surgery in group was $149.3 \mathrm{~min}$ with p value 0.0001 . Less intra operative complications were seen in group 1 patients. ( $\mathrm{p}$ value 0.0001 ). Immediate pulse was seen in all 50 patients of group 1 on operation table itself. Immediate thrill was observed in $98 \%$ in group 1 and $78 \%$ of group 2 patients (p value 0.0001 ). All the patients were followed post operatively every 1, 3 and 6 months during their visit to nephrologist and haemodialysis centre and postoperative functioning of fistula and fistula use in dialysis enquired; observation of the patency of fistula and thrill was done. In the follow up period, patency rate after 6 months was seen in more cases of group 1 ( $p$ value 0.00001 ).

\section{CONCLUSION}

End stage renal disease patients who need a long-life vascular access for haemodialysis, arteriovenous fistula which were created at the distal forearm with end to side radiocephalic anastomosis proved to have long life of more than 6 months with 3 mm arteriotomy diameter and had better outcome for the patient and comfortable for the surgeon.

\section{KEY WORDS}

RC -AV Fistula, $3 \mathrm{~mm}$ vs $<3 \mathrm{~mm}$, Arteriotomy Diameter, Maturation and Long Time Functioning Fistula.

HOW TO CITE THIS ARTICLE: Bharathi MS, Krishna KS, Kumar N, et al. Long-term patency rate of AV- fistula in relation to diameter of arteriotomy 3 mm vs <3 mm.J. Evolution Med. Dent. Sci. 2018;7(52):5539-5542, DOI: 10.14260/jemds/2018/1226

'Financial or Other Competing Interest': None.

Submission 26-10-2018, Peer Review 11-12-2018,

Acceptance 17-12-2018, Published 24-12-2018.

Corresponding Author:

Dr. Munagala Swatantra Bharathi,

Assistant Professor,

Department of Plastic Surgery,

Siddhartha Medical College,

Vijayawada, Andhra Pradesh, India.

E-mail:bharathisreya@gmail.com

DOI: $10.14260 /$ jemds/2018/1226

\section{(c) (i) $($ ) $\ominus$}

\section{BACKGROUND}

A vascular access is a haemodialysis patient's lifeline, because it makes life-saving haemodialysis treatments possible. Haemodialysis is a treatment for kidney failure that uses a machine to send the patient's blood through a filter, called a dialyzer, outside the body. The access is a surgically created vein used to remove and return blood during haemodialysis. A vascular access lets large amounts of blood flow continuously during haemodialysis treatments to filter as much blood as possible per treatment. Two types of vascular access designed for long-term use include the arteriovenous 
(AV) fistula and the AV graft. A third type of vascular access the venous catheter is for short-term use.

An AV fistula is a surgical connection made between an artery and a vein, created by a vascular specialist. An AV fistula is typically located in arm, however, if necessary, it can be placed in the leg. With an AV fistula, blood flows from the artery directly into the vein, increasing the blood pressure and amount of blood flow through the vein. The increased flow and pressure cause the veins to enlarge. The enlarged veins will be capable of delivering the amount of blood flow necessary to provide an adequate haemodialysis treatment. $\mathrm{AV}$ fistulas are the preferred vascular access for long-term dialysis because they last longer than any other dialysis access types, are less prone to infection, clotting and can be relied upon for predictable performance.

\section{Aim}

To evaluate the success rate in RC-AVF by arteriotomy diameter $3 \mathrm{~mm}$ vs $<3 \mathrm{~mm}$.

\section{Settings and Design}

It is a quasi-study of 100 cases.

\section{MATERIALS AND METHODS}

It is a quasi-experimental study. Between 2016 Dec to 2018 March., 100 patients were selected with ESRD referred by nephrologists to VIMS (Visakha institute of medical sciences super speciality hospital, Visakhapatnam). All patients were clinically examined by the operating surgeon for quality of the venous system of the upper limbs. Normal dual blood supply of forearm confirmed by Allen's test. Confirmed by Duplex ultrasound scanning performed for both arterial and venous system of upper limb. Renal function tests, haemoglobin \%, and clinical fitness for surgery evaluated. The sample size estimation was also done at conveniences.

\section{Surgical Procedure}

RC-AVF at the wrist is done in all patients with prior explained written consent, with end to side anastomosis by same surgeon using 7-0 polypropylene taper point needle, using magnification loups with magnification 4 times and using micro surgery steel instrument set.

A lazy-S longitudinal incision 4 of about $3-4 \mathrm{~cm}$ at distal forearm on radial aspect is given in all cases after local xylocaine $2 \%$ infiltration. ${ }^{5}$ Cephalic vein end is anastomosed with radial artery arteriotomy (End to Side). In 50 patients, arteriotomy of $3 \mathrm{~mm}$ diameter is given in Group 1 (Figure-1). In another 50 patients, arteriotomy $<3 \mathrm{~mm}$ (Group 2) given depending on the diameter of radial artery. On table immediate thrill and pulse noted. (Figure 2). Duration of time noted starting from local infiltration till wound closure. Throughout the procedure patient monitored by pulse oximeter.

100 patients of ESRD were included in the study with two groups, group 1 and group 2 .

\section{Study Variables}

Mean duration of surgery, intra operative bleeding, Immediate thrill, immediate pulse and postoperative functioning fistula for 1, 3, 6 months.

\section{Statistical Analysis}

Data is entered in Microsoft excel spread sheet and statistical analysis is done by using Microsoft excel and SPSS version 21(Statistical Package for Social Sciences). Categorical data is expressed as proportions and we used Pearson chi-squared test and Fishers exact test to test the significance. Quantitative data is expressed in Means and Standard deviation. A p - value of $<0.05$ is considered as statistically significant.

\section{RESULTS}

Taking gender into consideration, $74 \%$ were males. (Diagram 1) Mean age: $49.5+10.9$ years

Mean duration of surgery in both the groups resulted with a p value of 0.0001 (group 1-49.3 min) -Table-1

\begin{tabular}{|c|c|c|}
\hline & $<\mathbf{3 ~ m m ~ ( N = 5 0 )}$ & $\mathbf{3} \mathbf{~ m m ~ ( N = 5 0 )}$ \\
\hline Mean Duration of Surgery & $79.5+12.2$ & $49.3+5.8$ \\
\hline \multicolumn{2}{|c|}{ Table 1 } \\
\hline
\end{tabular}

Intra operative complications like bleeding was seen more with group 2 when compared with group 1 . (Table -2 with $\mathrm{p}$ value 0.0001 significant). Immediate pulse was observed on table for all cases in group 1. (P value 0.00001 Table -3). Immediate thrill was observed in $98 \%$ cases in group 1 where as it is $78 \%$ in group 2 (Significant $P$ value 0.0001 Table -4). Post operative follow up with functioning AV fistula results are compared after 1, 3 and 6 months with a palpable thrill. After one month there is functioning thrill in $98 \%$ in Group 1 cases but present only in $70 \%$ of cases of group 2 ( $\mathrm{P}$ value 0.00001 Table -5 ). At three months post operative period, functioning AV fistula is noted in $96 \%$ of cases in group 1 cases and only $70 \%$ of group 2 cases are having working AV fistula (P value 0.00001 Table -6). Six months post operative status: - (Table-7) functioning fistula is seen in $72 \%$ of group 1 cases and it is $6 \%$ only in group 2 (P value $<0.00001$. Statistically significant results are seen ( $p$ value $<0.05$ ) in group 1 when compared to group 2 cases, 3 $\mathrm{mm}$ diameter arteriotomy in radial artery 6,7 is more comfortable for surgeon in terms of duration of surgery, comfort, visibility, minimal bleeding complications both intra and post operatively and long term functioning of AV fistula in ESRD.

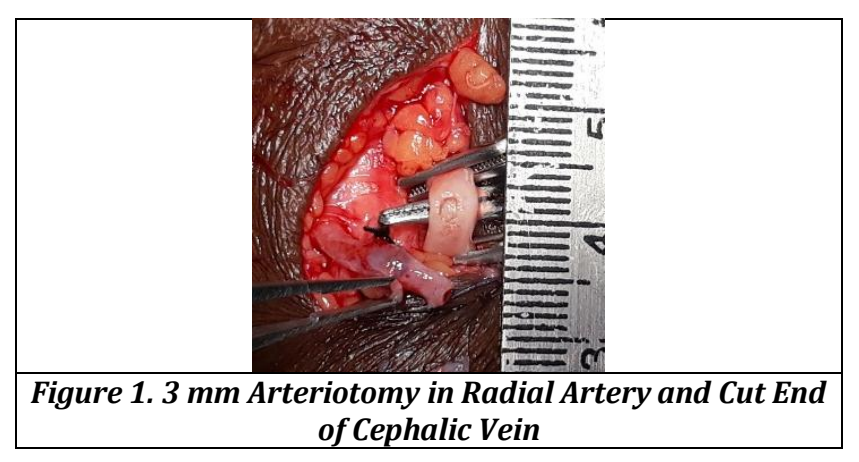




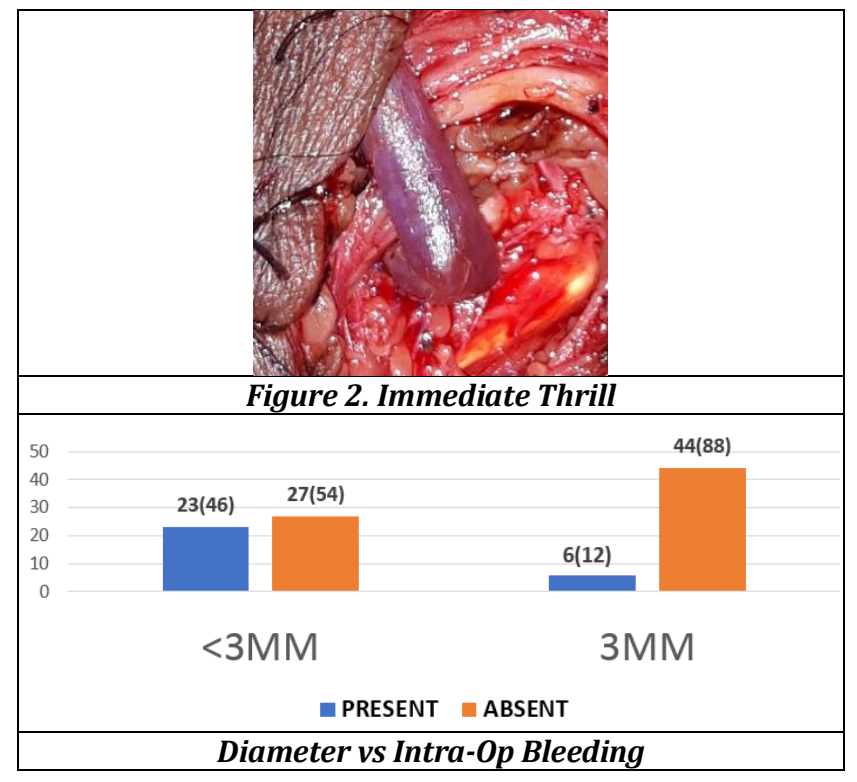

\begin{tabular}{|c|c|c|c|}
\hline & \multicolumn{2}{|c|}{ Intraoperative Bleeding } \\
\hline & & Present & Absent \\
\hline \multirow{2}{*}{ Diameter } & $<3 \mathrm{~mm} \mathrm{n}=50(\%)$ & $23(46)$ & $27(54)$ \\
\hline & $3 \mathrm{~mm} \mathrm{n}=50(\%)$ & $6(12)$ & $44(88)$ \\
\hline \multicolumn{4}{|c|}{ Table 2} \\
\hline
\end{tabular}

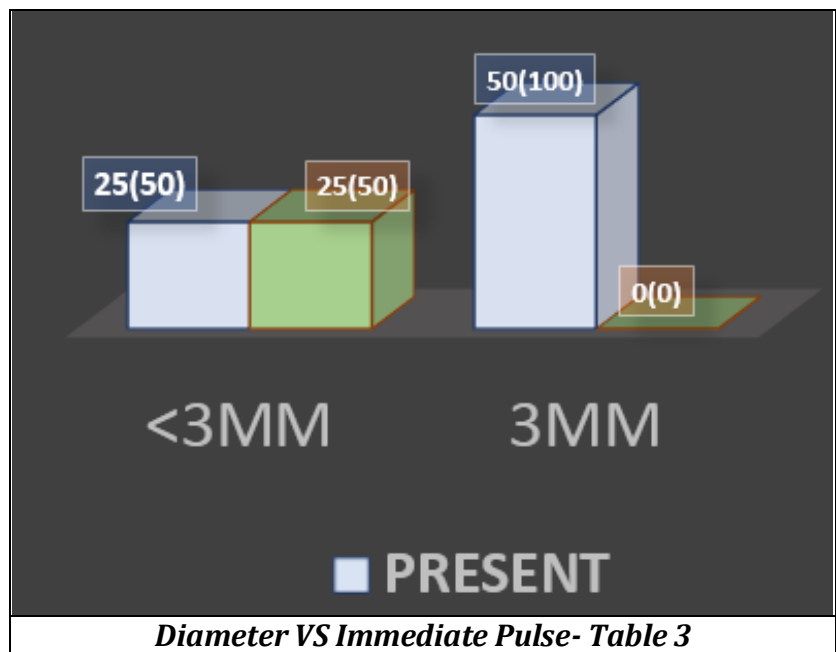

\begin{tabular}{|c|c|c|c|}
\hline & \multicolumn{2}{|c|}{ Immediate Pulse } \\
\hline & & Present & Absent \\
\hline \multirow{2}{*}{ Diameter } & $<3 \mathrm{~mm} \mathrm{n}=50(\%)$ & $25(50)$ & $25(50)$ \\
\hline & $3 \mathrm{~mm} \mathrm{n}=50(\%)$ & $50(100)$ & $0(0)$ \\
\hline \multicolumn{4}{|c|}{ Table 3} \\
\hline
\end{tabular}

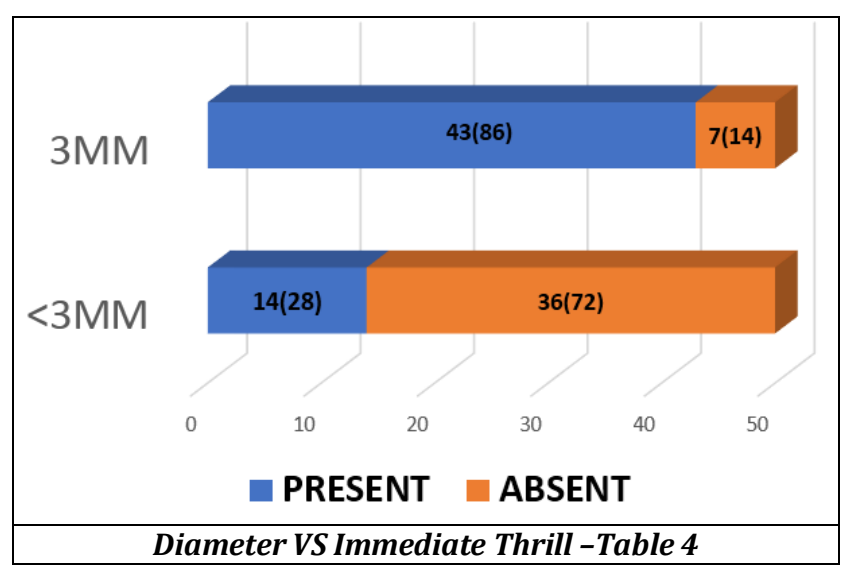

\begin{tabular}{|c|c|c|c|}
\hline \multicolumn{2}{|c|}{} & \multicolumn{2}{c|}{ Immediate Thrill } \\
\cline { 3 - 4 } Diameter & $<3 \mathrm{~mm} \mathrm{n}=50(\%)$ & Present & Absent \\
\cline { 2 - 4 } & $3 \mathrm{~mm} \mathrm{n}=50(\%)$ & $43(86)$ & $36(72)$ \\
\hline \multicolumn{2}{|c|}{ Table 4 } & $7(14)$ \\
\hline
\end{tabular}

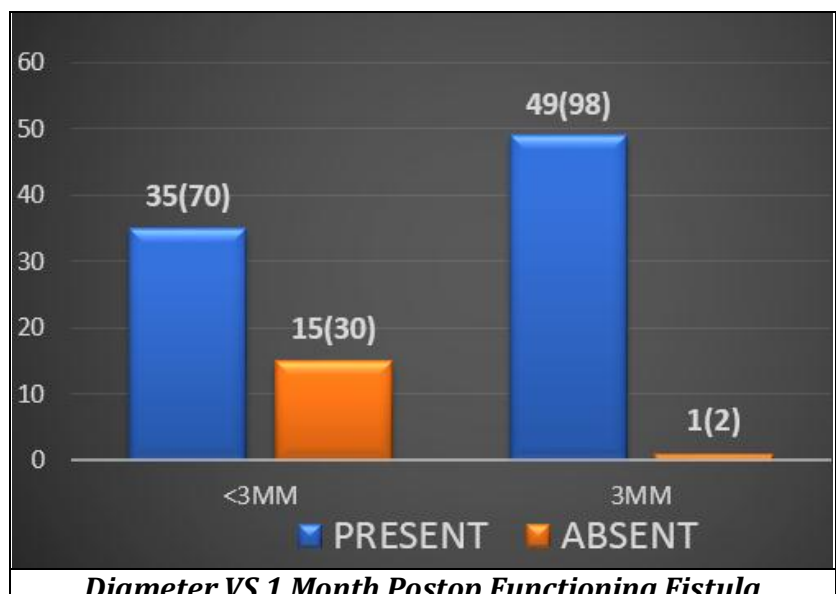

Diameter VS 1 Month Postop Functioning Fistula

\begin{tabular}{|c|c|c|c|}
\hline \multicolumn{2}{|c|}{} & \multicolumn{2}{c|}{$\begin{array}{c}\text { Month Postop Functioning } \\
\text { Fistula }\end{array}$} \\
\cline { 2 - 4 } \multicolumn{2}{|c|}{} & Present & Absent \\
\hline \multirow{2}{*}{ Diameter } & $<3 \mathrm{~mm} \mathrm{n}=50(\%)$ & $35(70)$ & $15(30)$ \\
\cline { 2 - 4 } & $3 \mathrm{~mm} \mathrm{n}=50(\%)$ & $49(98)$ & $1(2)$ \\
\hline \multicolumn{3}{|c|}{ Table 5 } \\
\hline
\end{tabular}

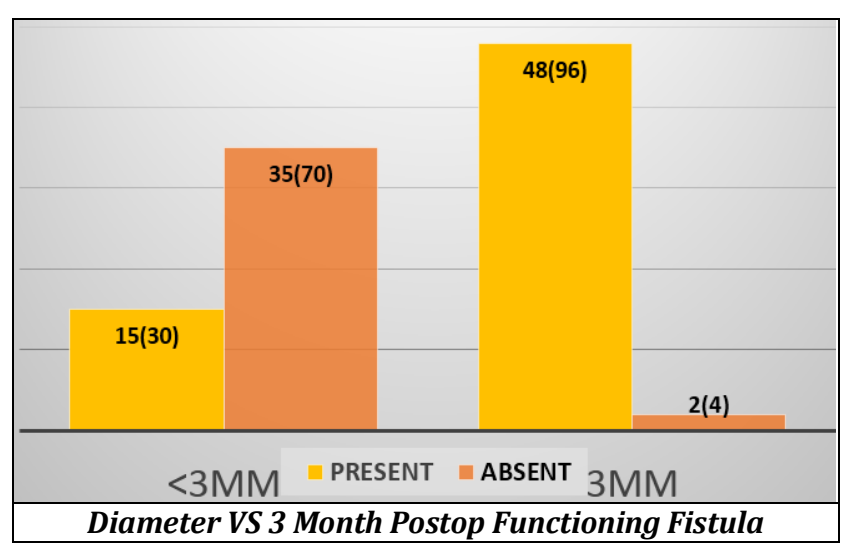

\begin{tabular}{|c|c|c|c|}
\hline \multicolumn{2}{|c|}{} & $\begin{array}{c}\text { Postop Functioning } \\
\text { Fistula }\end{array}$ \\
\cline { 3 - 4 } \multicolumn{2}{|c|}{} & $\begin{array}{c}\text { Present } \\
\text { Absent }\end{array}$ & Abs \\
\hline \multirow{2}{*}{ Diameter } & $<3 \mathrm{~mm} \mathrm{n}=50(\%)$ & $15(30)$ & $35(70)$ \\
\cline { 2 - 4 } & $3 \mathrm{~mm} \mathrm{n}=50(\%)$ & $48(96)$ & $2(4)$ \\
\hline \multicolumn{3}{|c|}{ Table 6 } \\
\hline
\end{tabular}

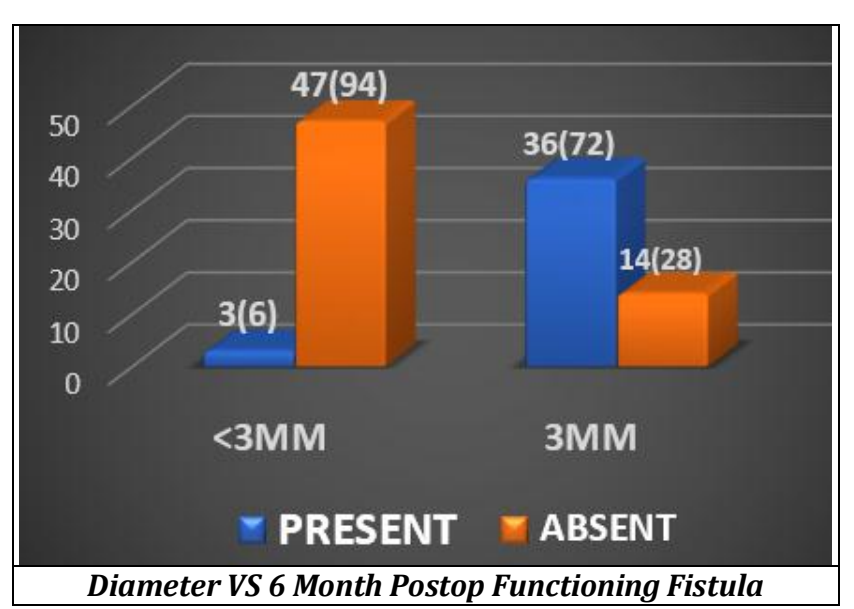




\begin{tabular}{|c|c|c|c|}
\hline \multicolumn{2}{|c|}{} & \multicolumn{2}{|c|}{$\begin{array}{c}\text { Month Postop Functioning } \\
\text { Fistula }\end{array}$} \\
\cline { 3 - 4 } \multicolumn{2}{|c|}{} & Present & Absent \\
\hline \multirow{2}{*}{ Diameter } & $<3 \mathrm{~mm} \mathrm{n}=50(\%)$ & $3(6)$ & $47(94)$ \\
\cline { 2 - 4 } & $3 \mathrm{~mm} \mathrm{n}=50(\%)$ & $14(28)$ & $36(72)$ \\
\hline \multicolumn{3}{|c|}{ Table 7 }
\end{tabular}

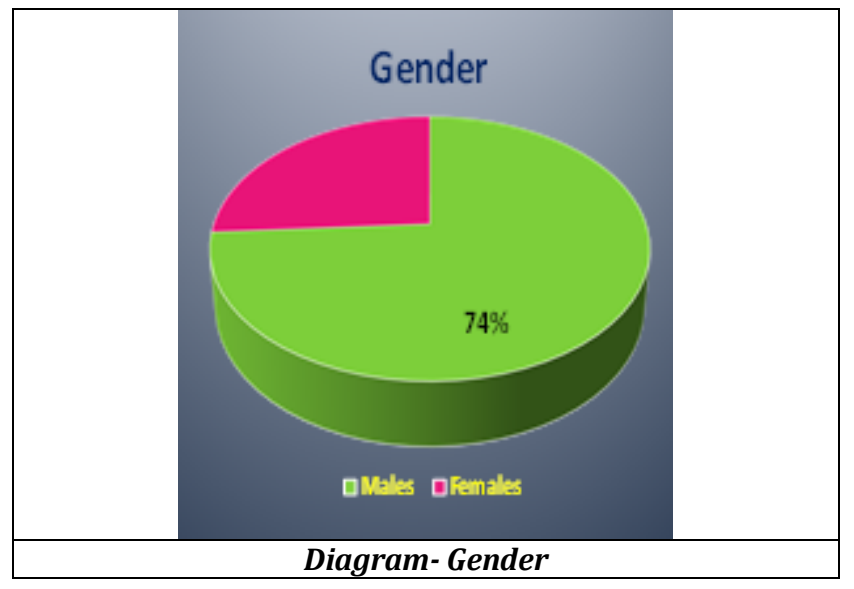

\section{DISCUSSION}

The autologous arteriovenous fistula ${ }^{8}$ is the acceptable gold standard mode of vascular access for haemodialysis in terms of longevity patient morbidity and health care costs. Distal radio cephalic end to side arteriovenous fistula is a boon for ESRD patients. A study was conducted with 100 ESRD patients undergoing haemodialysis, $50 \%$ of them $3 \mathrm{~mm}$ diameter arteriotomy was done and another 50 of them $<3$ $\mathrm{mm}$ diameter is considered. The aim of the study is to evaluate the efficacy in maturation and long-life functioning fistula. The arteriotomy of $3 \mathrm{~mm}$ diameter is taken as criterion for the reasons-

1. Flow into cephalic vein (Swing segment) 9,10 with adequate velocity produces a spiral laminar flow and a turbulence is obtained. A laminar flow in the arterial limb and a complex flow field in the swing segment in a patient specific side to end fistula, there will both multidirectional reciprocating disturbed flow and spiral laminar flow. These causes turbulent eddies leading to high frequency oscillations of the wall and shear stress vectors. These hemodynamic forces have obvious implication on initiation of venous wall thickening, neo intima formation which leads to early fistula maturation and long-time maintenance of that forces.

2. Adequate patency is maintained post operatively, ${ }^{11}$

3. Chances of thrombus formation ${ }^{12}$ is minimal due to adequate velocity of blood flow which flushes the thrombus any formed

4. Adequate diameter of $3 \mathrm{~mm}$ is almost equivalent to cephalic vein end diameter which is comfortable for the surgeon to anastomose with less eye strain. ${ }^{4}$ Distal RCAV fistula has long swing segment which is needed for haemodialysis.

Diameter $3 \mathrm{~mm}$ arteriotomy could be taken for only those patients with adequate arterial diameter that is decided after colour Doppler and on table decision. Not in all arteries $3 \mathrm{~mm}$ is taken for the risk of steal phenomenon due to post operative kink of radial artery and in this study in one case it is observed. Intra operative bleeding complications could be minimized by $3 \mathrm{~mm}$ arteriotomy by the way surgical anastomosis is easy but with lesser size $(<3 \mathrm{~mm})$ may lead to further narrowing of fistula lumen and thrombogenic due to more tissue handling. Post operatively functioning fistula is assessed 1, 3 and 6 months which showed that $3 \mathrm{~mm}$ diameter arteriotomy AV fistulas have long functioning life.

\section{CONCLUSION}

End stage renal disease patients who need a long-life vascular access for haemodialysis, arteriovenous fistula which were created at distal forearm by end-to-side radiocephalic anastomosis with a $3 \mathrm{~mm}$ arteriotomy diameter proved to have long life and had better outcome for the patient and at the same time was comfortable for the surgeon.

\section{REFERENCES}

[1] Dixon BS. Why don't fistulas mature? Kidney International 2006;70(8):1413-22.

[2] Rodriguez JA, Armadans L, Ferrer E, et al. Stopping long term dialysis. Nephrology Dialysis Transplantation 2008;15(3):402-8.

[3] Konner K, Nonnast-Daniel B, Ritz E. The arteriovenous fistula. J American Soc Nephrol 2003;14(6):1669-80.

[4] Bashar K. Vascular surgery - a global prospective. Int J Surg 2015.

[5] Ismail A, Abushouk AI, Bekhet $\mathrm{AH}$, et al. Regional versus local anesthesia for arteriovenous fistula creation in end-stage renal disease: a systematic review and meta-analysis. J Vasc Access 2017;18(3):177-84.

[6] Farber A, Imrey PB, Huber TS, et al. Multiple preoperative and intraoperative factors predict early fistula thrombosis in the Haemodialysis Fistula Maturation Study. J Vasc Surg 2016;63(1)163-70.e6.

[7] Voormolen EH, Jahrome AK, Bartels LW, et al. Nonmaturation of arm arteriovenous fistulas for haemodialysis access: a systematic review of risk factors and results of early treatment. J Vasc Surg 2009;49(5):1325-36.

[8] Lee KG, Chong TT, Goh N, et al. Outcomes of arteriovenous fistua creation, effect of preoperative vein mapping and predictors of fistula success in incident haemodialysis patients: a single-centre experience. Nephrology (Carlton) 2017;22(5):382-7.

[9] Remuzzi A, Bozzetto M, Brambilla P. Is shear stress the key factor for AVF maturation? J Vasc Access 2017;18(Suppl l):10-4.

[10] Corpataux JM, Haesler E, Silacci P, et al. Low-pressure environment and remodelling of the forearm vein in Brescia-Cimino haemodialysis access. Nephrology Dialysis Transplantation 2002;17(6):1057-62.

[11] Lee JY, Kim YO. Pre-existing arterial pathologic changes affecting arteriovenous fistula patency and cardiovascular mortality in haemodialysis patients. Korean J Intern Med 2017;32(5):790-7.

[12] Smith GE, Souvoullos P, Cayton T, et al. Future research directions to improve fistula maturation and reduce access failure. J Vasc Access 2016. 